\title{
Tribological properties of duplex plasma oxidised, nitrided and PVD coated Ti-6Al-4V
}

\author{
G. Cassar ${ }^{\text {a,* }}$, S. Banfield ${ }^{\text {a,b }}$, J.C. Avelar-Batista Wilson ${ }^{\text {b }}$, J. Housden ${ }^{\text {b }}$, A. Matthews ${ }^{\text {a }}$, A. Leyland ${ }^{\text {a }}$ \\ a Department of Materials Science and Engineering, University of Sheffield, Sir Robert Hadfield Building, Mappin St., Sheffield S1 3JD, UK \\ b Tecvac Ltd, Buckingway Business Park, Swavesey, Cambridge CB24 4UG, UK
}

\section{A R T I C L E I N F O}

\section{Article history:}

Received 8 April 2011

Accepted in revised form 14 July 2011

Available online 23 July 2011

\section{Keywords:}

Triode plasma diffusion

PVD

Ti-6Al-4V

Scratch-adhesion

Wear

\begin{abstract}
A B S T R A C T
Sequential triode plasma oxidation and nitriding have been used to provide enhanced load support for physical vapour deposited (PVD) hard coatings. The diffusion process has been designed to maximise process efficiency and coating adhesion, thereby significantly improving the tribological properties of the Ti-6Al-4V alloy - particularly at high contact pressures. This has been demonstrated using unlubricated linear reciprocating-sliding ball-on-plate wear tests and micro-scratch adhesion testing. Also, surface microprofilometry, nano/micro-indentation hardness testing, scanning electron microscopy (SEM), energydispersive X-ray spectroscopy (EDX), X-ray diffraction (XRD), and glow-discharge optical emission spectroscopy (GDOES) data are presented to corroborate the effect of the several plasma diffusion processes and duplex diffusion/coating combinations discussed here. The results presented show that the novel processing technique developed permits the use of oxygen diffusion in order to obtain relatively large case depths in shorter treatment times without compromising the adhesion strength of subsequently deposited PVD layers.
\end{abstract}

(c) 2011 Elsevier B.V. All rights reserved.

\section{Introduction}

Titanium alloys are exceptional materials in terms of both their mechanical and physical properties; unfortunately, their wear performance is often not satisfactory, restricting their application to non-tribological systems. Surface contact loads can result in rapid breakdown of the nascent oxide film, with consequent severe surface damage and seizure. Such poor tribological performance is generally attributed to several factors, including high chemical reactivity and a consequent high coefficient of friction [1], which results in seizure [2], galling [3] and fretting [4] damage. Also, the low hardness and shear modulus of (particularly) hcp titanium lead to a higher friction coefficient, metallic wear and adhesive transfer of material when subjected to sliding contact [5,6]. In addition, the lower thermal conductivity of Ti compared to other metals hinders heat dissipation away from contacts, thereby increasing wear [7].

The poor tribological performance of current commercial titanium alloys makes necessary the use of surface engineering techniques to expand the range of possible fields of application, especially in engineering applications involving relative motion between components in loaded contact. Most surface hardening techniques, traditionally extremely effective on other materials, give limited improvement

\footnotetext{
* Corresponding author. Tel.: + 3562340 2140; fax: + 35621343577. E-mail address: glenn.cassar@um.edu.mt (G. Cassar).
}

on the softer titanium substrate. Coatings deposited on substrates with low elastic moduli are known to be severely limited by the substrate's poor load-bearing capacity [8] - mainly due to the creation of a stepped transition in material properties. Thus, although hard coating deposition is widely documented in the literature, most of the treatments applied lead to appreciable wear reduction only at lower contact loads. At higher loads, the high hardness and tribochemical inertness of many ceramic coatings cannot be fully taken advantage of, since catastrophic failure tends to occur if the substrate deforms.

Conversely, when used as a single process, thermochemical conversion treatments often create a more gradual transition in properties from the tough bulk to the hard (and stiff) surface, but on the other hand may not sufficiently alter the surface chemistry to prevent adhesive wear and galling under tribo-contact. A potential solution to both of these difficulties is to provide load-support using a diffusion treatment before any subsequent hard coating is deposited; such sequential methods are often referred to as 'duplex' or 'hybrid' techniques $[9,10]$. One principal concern in the deposition of hard coatings following substrate diffusion treatment is the adhesion of such coating to surface compound layers that may be developed during the diffusion process. This is particularly the case for diffusion processes using oxygen - since the development of a thick titanium oxide layer can lead to rapid spallation of commonly-applied PVD tribological coatings such as TiN and CrAlN. In fact, poor adhesion is often a limiting factor in coating performance for many applications and it is therefore necessary to create a strong bond between the deposited layer and the substrate material. 
In this research, the load-bearing capacity of triode plasma oxidised, nitrided and TiN/CrAlN coated Ti-6Al-4V alloy is investigated. In particular, the tribological response of different diffusion treatments to linear reciprocating-sliding ball-on-plate wear tests is compared and the scratch adhesion strength of the two PVD coatings on diffusion-treated substrates is discussed.

\section{Experimental details}

The notional chemical composition of the Ti-6Al-4V alloy used was $6.01 \mathrm{wt} . \% \mathrm{Al}, 4.08 \mathrm{wt}$ \% V, balance Ti. The test coupons had a core hardness of $375 \pm 10 \mathrm{HK}_{0.025}$ and were polished to a mirror finish, with a measured mean surface roughness, $R_{a}$, of $0.03 \pm 0.01 \mu \mathrm{m}$.

The base material was diffusion-treated by plasma nitriding or combined oxidation/nitriding in a modified Tecvac IP70L commercial coating system, using a low-pressure d.c. triode configuration $[9,11]$ and additional radiative heating. Triode enhanced-plasma diffusion treatments were carried out at a substrate temperature of $700{ }^{\circ} \mathrm{C}$ in a mixture of $70 \%$ partial pressure of nitrogen or oxygen and $30 \%$ partial pressure of argon, at a total gas pressure of $0.4 \mathrm{~Pa}$.

The specimens, untreated or diffusion-treated, were coated either with TiN, deposited using an electron-beam (EB) plasma-assisted (PA) PVD system (Tecvac IP70 coater) or with CrAlN, deposited using a twin-EB PAPVD machine (Tecvac IP35 coater). Thermionic plasma enhancement was provided by an additional electron-emitting cathode in the form of a hot tungsten filament, biased at $-200 \mathrm{~V}$, positioned near the base of the chamber, adjacent to the vapour source(s). Samples were firstly diode sputter cleaned in Ar at $2.0 \pm$ $0.1 \mathrm{~Pa}$ chamber pressure and $1000 \mathrm{~V}$ substrate negative bias, then a thin interlayer with a thickness between 0.1 and $0.2 \mu \mathrm{m}$ was deposited ( $\mathrm{Ti}$ in the case of $\mathrm{TiN}$, and $\mathrm{Cr}+\mathrm{CrN}$ for $\mathrm{CrAlN}$ ) under a pressure of $0.3 \mathrm{~Pa}$ and triode conditions. Finally, the ceramic coating layer was deposited for approximately $100 \mathrm{~min}$, to give a total thickness of $2.8 \pm 0.2 \mu \mathrm{m}$ in the case of TiN, and $2.0 \pm 0.2 \mu \mathrm{m}$ for CrAlN. During the coating stage the maximum substrate temperature ranged between 400 and $450{ }^{\circ} \mathrm{C}$.

\subsection{Characterisation and wear testing}

Knoop microindentation hardness measurements were performed on polished substrate cross-sections using a Mitutoyo HM microhardness tester, set at a load of $25 \mathrm{gf}(1 \mathrm{gf}=9.81 \mathrm{mN})$ and a $20 \mathrm{~s}$ dwell time. The test method used followed the relevant standard for Knoop hardness testing of metallic materials - BS EN ISO 4545-1:2005 [12]. The first indent impression was positioned at a distance $>8 \mu \mathrm{m}$ from the surface, to minimise the effects of the unconstrained surface buckling under load. Surface nanoindentation measurements were performed using a Hysitron Inc. Triboscope ${ }^{\mathrm{TM}}$ equipped with a Berkovich triangular-pyramidal diamond indenter with an average tip radius of curvature of approximately $150 \mathrm{~nm}$. Fifteen indentations were made for each sample at maximum loads of around $10 \mathrm{mN}$ and $5 \mathrm{mN}$ for coatings and diffusion-treated samples, respectively. For consistency, measured Knoop cross-sectional microindentation hardness values have also been converted to GPa.

A Veeco Dektak 150 stylus profilometer was used to measure the sample surface roughness and wear scar volumes. The $12.5 \mu \mathrm{m}$ radius diamond tip was loaded with a force of $30 \mathrm{mg}$ and the scan duration was set such that the traversing resolution was better than $0.05 \mu \mathrm{m}$; the vertical resolution was less than $0.01 \mu \mathrm{m}$. Three-dimensional (3D) maps were also obtained using multiple scans, which were integrated using Vision ${ }^{\circledR}$ 3D analysis software. The number of parallel scans was set such that a minimum lateral resolution of $25 \mu \mathrm{m}$ was obtained.

Glancing-angle X-ray diffraction studies were performed using a Siemens D5000 diffractometer ( $\mathrm{Cu} K_{\alpha}$ radiation) operated in SeemanBohlin geometry at a glancing angle of $2^{\circ}$ with step size of $0.02^{\circ}$, and a step time of $5 \mathrm{~s}$. The tube acceleration voltage and current used were $40 \mathrm{kV}$ and $30 \mathrm{~mA}$ respectively.

GDOES measurements were made in Ar plasma using a Jobin Yvon (Horiba) r.f. GD-Profiler. The instrument was equipped with a copper anode (4 mm diameter) glow-discharge source and operated using a $650 \mathrm{~Pa} \mathrm{Ar}$ pressure and $30 \mathrm{~W}$ r.f. power. For each sample, the composition depth profiles extended through the surface layer/s into the bulk Ti alloy using a data acquisition frequency of $20 \mathrm{~Hz}$ for the first $120 \mathrm{~s}$, reducing to $2 \mathrm{~Hz}$ until the test was completed. The calibration was carried out using a series of samples with known elemental composition, including 99.99\% pure $\mathrm{Ti}, \mathrm{Cr}$ and $\mathrm{Al}$ and stoichiometric $\mathrm{CrN}$ and TiN. Automatic background corrections and calibration (pre-set using certified reference materials) were also employed. The depth of each scar was measured using surface microprofilometry. In turn, this allowed for the quantification of sputter rates and thus plotting of concentration-depth profiles.

A commercial VTT scratch tester was used to assess coating adhesion. This was equipped with a conical diamond indenter of radius $200 \mu \mathrm{m}$ and an included angle of $120^{\circ}$. A loading rate of $10 \mathrm{~N} / \mathrm{mm}$ was used and the sample was traversed at a speed of $10 \mathrm{~mm} / \mathrm{min}$. A pre-load of $5 \mathrm{~N}$ was also applied to allow identification of the starting position of the scratch track. Optical microscopy was used to determine the ultimate critical loads, defined in Table $1 . L_{C 1}, L_{C 2}$ and $L_{C 3}$ were determined from a set of three scratches on each sample and their values based on the observation of the damage events as described in BS EN 1071-3:2005 [13].

Wear tests were performed using a low-frequency $(5 \mathrm{~Hz})$ reciprocating-sliding tribometer, connected to a computer monitoring the dynamic coefficient of friction (in both sliding directions), relative humidity and temperature. Tests were performed by applying a normal load of $13.5 \pm 0.1 \mathrm{~N}$ to a static ball of diameter $10 \mathrm{~mm}$. The ball materials used were WC-7 wt.\% Co and single crystal $\mathrm{Al}_{2} \mathrm{O}_{3}$ (sapphire). The WC-Co ball used in this work had a hardness of 20.7 GPa while sapphire had a hardness of $31.2 \mathrm{GPa}$. The maximum static contact stress for a $10 \mathrm{~mm}$ ball pressed against a Ti-6Al-4V substrate was $1.09 \mathrm{GPa}$ and $1.16 \mathrm{GPa}$ when using WC-Co and sapphire, respectively. The loading regime was selected such that, at $13.5 \mathrm{~N}$ load, the resultant initial contact pressure was well in excess of the substrate yield strength.

The sample designations used in this work are presented in Table 2. For instance, a sample which has been nitrided at $-200 \mathrm{~V}$ and subsequently coated with CrAlN is designated as LV-TPN + CrAlN.

\section{Results and discussion}

Fig. 1 shows diffraction patterns for Ti-6Al-4V samples nitrided at low $(-200 \mathrm{~V})$ and high $(-1000 \mathrm{~V})$ substrate bias at $700{ }^{\circ} \mathrm{C}$ for $4 \mathrm{~h}$. New peaks corresponding to $\delta$-TiN (ICDD file \#38-1420), and $\varepsilon-\mathrm{Ti}_{2} \mathrm{~N}$ (ICDD file \#17-0386) phases become apparent following triode plasma nitriding. It is clear that a higher nitride peak intensity is obtained at the high bias voltage. The thin compound layer $(<0.25 \mu \mathrm{m})$ formed on LV-TPN consisted mainly of tetragonal $\mathrm{Ti}_{2} \mathrm{~N}$, while the thicker compound layer $(1.45 \pm 0.1 \mu \mathrm{m})$ formed on HV-TPN contained significant amounts of face-centred cubic TiN. EDX analysis of the treated surfaces showed that the outer stratum of the

\section{Table 1}

Description of failure events corresponding to critical loads.

\begin{tabular}{lll}
\hline $\begin{array}{l}\text { Critical } \\
\text { load }\end{array}$ & Description of failure & Observable trait \\
\hline$L_{C 1}$ & $\begin{array}{l}\text { Cohesive failure within the } \\
\text { coating }\end{array}$ & $\begin{array}{l}\text { Onset of cracking } \\
L_{C 2}\end{array}$ \\
$\begin{array}{l}\text { Adhesive failure of the } \\
\text { coating } \\
L_{C 3}\end{array}$ & $\begin{array}{l}\text { Substrate first exposed - typically visible } \\
\text { through the coating }\end{array}$ & $\begin{array}{l}\text { in the form of edge chipping } \\
\text { Complete spalling of the coating from the } \\
\text { centre of the scratch track }\end{array}$ \\
\hline
\end{tabular}


Table 2

Sample designation system.

\begin{tabular}{ll}
\hline Bias potential & Triode-plasma diffusion process \\
\hline Low voltage $(-200 \mathrm{~V})(\mathrm{LV})$ & Oxidation (TPO) \\
High voltage $(-1000 \mathrm{~V})(\mathrm{HV})$ & Nitriding (TPN) \\
Low voltage followed by high voltage & Oxidation followed by nitriding (TPON) \\
$\quad$ treatment $(\mathrm{LHV})$ & \\
\hline
\end{tabular}

compound layer is comprised primarily of TiN while, according to models such as those presented in [14,15], $\mathrm{Ti}_{2} \mathrm{~N}$ (possibly mixed with TiN) forms the rest of the compound layer. The relative intensities of the dominant peaks also appear to depend on the negative bias applied. The $\varepsilon-\mathrm{Ti}_{2} \mathrm{~N}(210)$ increases in intensity with increasing processing voltage. This difference is related to changes in nitrogen diffusion within the $\alpha$-Ti alloy (and the consequent transformation into nitride phases) according to the energy imparted to the surface by the arriving ionic and neutral species. Also, the presence of some residual $\alpha$-Ti is noticeable. This may be attributed to some contribution to the diffracted signal by the underlying nitrogenstabilised $\alpha$-layer; however, the intensity of the $\alpha$-Ti(002) peak appears to be almost constant irrespective of any nitriding treatment. This is in agreement with work by Fouquet et al. [16] who found difficulty in nitriding this $\alpha$-Ti phase in (002) orientation - even after $12 \mathrm{~h}$ of plasma processing. This stems from a greater difficulty in nitriding $\alpha$-Ti grains with their basal planes parallel to the surface and to the faster diffusion coefficient along the $a$-axis as opposed to that parallel to the $c$-axis $[16,17]$.

Fig. 1 also shows the increased formation of the $\delta$ phase during HVtreatments. There is evidence suggesting that the diffusivity of nitrogen through $\varepsilon-\mathrm{Ti}_{2} \mathrm{~N}$ is between one and two orders of magnitude higher than for $\delta$-TiN above a temperature of $700^{\circ} \mathrm{C}[18,19]$. Thus, the change in prevalent nitride phase can reduce the mobility of nitrogen through the compound layer and into the substrate, thereby reducing the case depth achieved. This has to be added to the fact that HVtreatments also generate thicker nitride compound layers, lengthening this barrier region. In fact, the coefficient of diffusion for nitrogen in nitride phases can be more than 30 times smaller than for $\alpha$-Ti $[20,21]$, depending on the composition of the compound layer and resulting diffusion conditions. GDOES compositional-depth profiles of HV- and LV-TPN processes are shown in Fig. 2. The nitrogen content in the LV-TPN samples clearly decreases more slowly with increasing analysis depth. The figure also shows the higher accumulation of nitrogen (reaching around 50 at.\% at the surface) when nitriding at a higher cathode bias voltage, while significantly deeper nitrogen

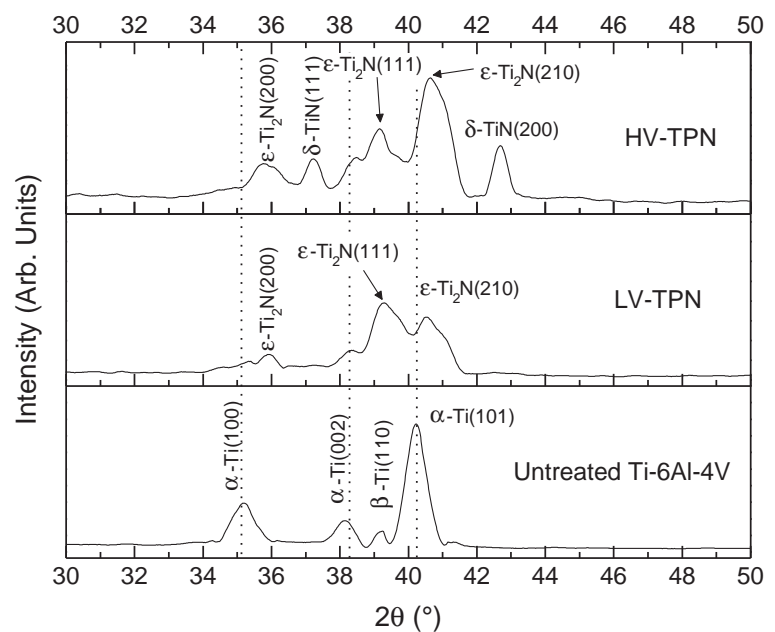

Fig. 1. GAXRD ( $2^{\circ}$ angle of incidence) diffraction patterns of untreated and nitrided Ti$6 \mathrm{Al}-4 \mathrm{~V}$.

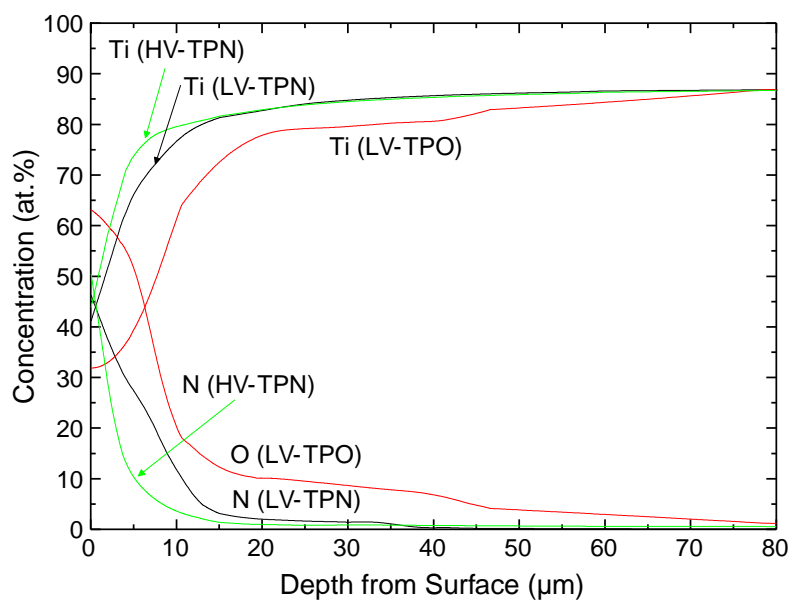

Fig. 2. GDOES chemical-depth profiles of LV-TPN, HV-TPN and LV-TPO-treated Ti-6Al$4 \mathrm{~V}$. All treatments were carried out at $700{ }^{\circ} \mathrm{C}$ for a total of $4 \mathrm{~h}$. Scan lines for Al, V and impurities are excluded, for clarity.

penetration can be observed for samples treated at low voltage. This is reflected in the hardness-depth profiles shown in Fig. 3, which clearly indicate a larger diffusion-strengthened nitrogen solid solution zone below the compound layer for LV-TPN compared to HV-TPN. The effect of these differences in chemical- and hardness-depth profiles generated by different voltages on the tribological properties of Ti$6 \mathrm{Al}-4 \mathrm{~V}$ has been discussed in detail in [22]. LV-TPN, both as a single treatment process and (particularly) in 'duplex' combination with a hard PVD coating was shown to give large reductions in wear rate.

Similar LV treatments were carried out using oxygen instead of nitrogen. The rate of oxygen diffusion in $\alpha$-Ti is known to be much higher than that of nitrogen at a given temperature $[20,23]$ and, more importantly, can be maintained at its maximum potential irrespective of whether or not a compound layer is formed at the surface during the oxidation process. In fact, the diffusion coefficient for oxygen in rutile $\mathrm{TiO}_{2}$ is - unlike the reduced nitrogen activity in $\mathrm{TiN} / \mathrm{Ti}_{2} \mathrm{~N}$ - about 50 times higher than in $\mathrm{Ti}(\mathrm{O})$-metal at the same temperature [23]. In other words, an oxide compound layer will not inhibit the growth of the solid solution strengthened zone over time and therefore the case depth achieved will be deeper when compared to any equivalent nitriding process.

Fig. 2 also shows the GDOES chemical depth profile of a Ti-6Al-4V sample which has been oxidised at $700{ }^{\circ} \mathrm{C}$ for $4 \mathrm{~h}$. It is clear that there

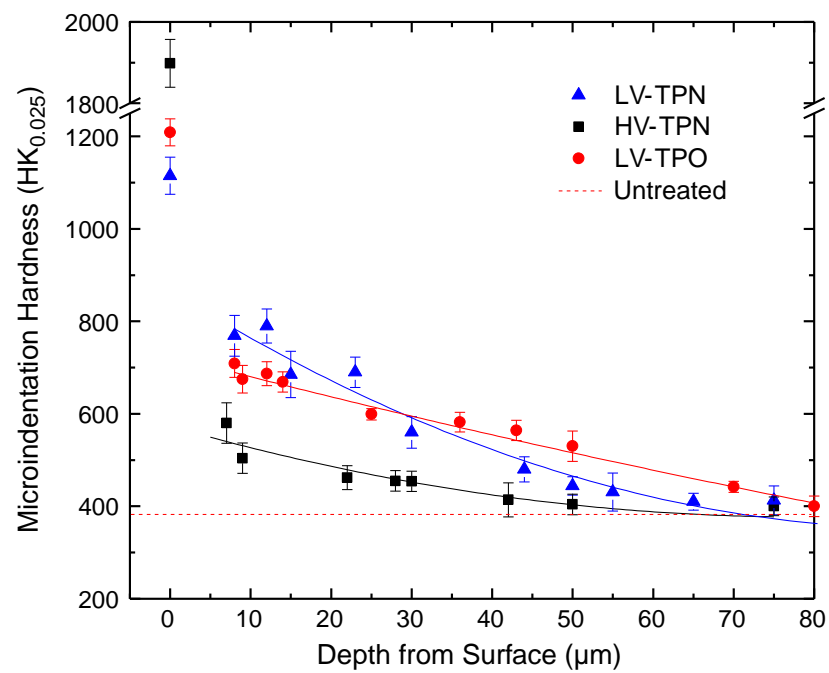

Fig. 3. Knoop cross-sectional microhardness measurements of LV-TPN, HV-TPN and LVTPO treated Ti-6Al-4V. Samples were treated at $700{ }^{\circ} \mathrm{C}$ for $4 \mathrm{~h}$. 
is a deeper penetration of oxygen compared to nitrogen under otherwise identical process conditions. Similarly, at this temperature the LV-TPO sample shows a significantly deeper hardened case (Fig. 3) compared to nitrided samples treated for the same duration and using the same bias voltage. These differences are a result of both the higher diffusion coefficient of oxygen through the Ti lattice and the differences in the permeability of the compound layer. However, the increase in solute penetration is unfortunately accompanied by a thicker oxide compound layer compared to the equivalent nitride compound. Following the LV-TPN treatment performed at $700{ }^{\circ} \mathrm{C}$ for $4 \mathrm{~h}$, the nitride compound layer is around $0.25 \mu \mathrm{m}$ thick while the LVTPO treatment forms an oxide layer approaching $1.9 \mu \mathrm{m}$ in thickness. XRD results show that the latter chiefly comprised mixtures of the anatase and rutile polymorphs of $\mathrm{TiO}_{2}$.

\subsection{Scratch-adhesion testing}

Unfortunately, the adhesion of PVD coatings on Ti-6Al-4V can be severely compromised by the presence of an oxide layer generated by an oxidation process. Fig. 4 shows that, as the oxidation process continues (from 2 to $4 \mathrm{~h}$ ), the adhesion of a subsequently deposited TiN coating diminishes compared to TiN deposited on the untreated substrate. When the applied load is still very low, cracking occurs immediately in the unsupported coating, while $\sim 8 \mathrm{~N}$ load is needed to initiate cohesive failure (marked by $L_{C 1}$ ) in the coating deposited on a substrate subjected to a $2 \mathrm{~h}$ TPO process. However, this apparent advantage of the TPO pre-treated substrate is soon lost - since adhesive failure, marked by $L_{C 2}$, occurs more readily in the latter. This clearly shows a loss of adhesive strength at the coating/substrate interface, rather than cohesive failure in the coating itself. The situation deteriorates further when the Ti-alloy substrate is subjected to a $4 \mathrm{~h}$ oxidation process prior to PVD coating. In this case, the TiN film visibly peels off the oxygen-treated substrate when the slightest load is applied.

In order to address the problem regarding the adhesion of a PVD coating to a previously oxidised Ti surface (and based on the results discussed above), two approaches were taken to try to eliminate the oxide surface compound layer. The first method employed a rationale similar to a 'boost-diffuse' thermochemical treatment cycle [24] whereby the oxidation procedure was intermittent or pulsed, such that the oxide layer generated during the TPO (boost) stage is consumed during the diffusion stage. The relatively short individual oxidation steps maintained an oxide layer sufficiently thin to be easily consumed (and resputtered) during the subsequent $\mathrm{Ar}$ plasma heating. In this case, the sample was exposed to an oxygen plasma for $15 \mathrm{~min}$ and then maintained at the $700{ }^{\circ} \mathrm{C}$ treatment temperature in a pure Ar plasma for a further $15 \mathrm{~min}$. These two steps were repeated eight times, for a total duration of $4 \mathrm{~h}$. The diffractogram in

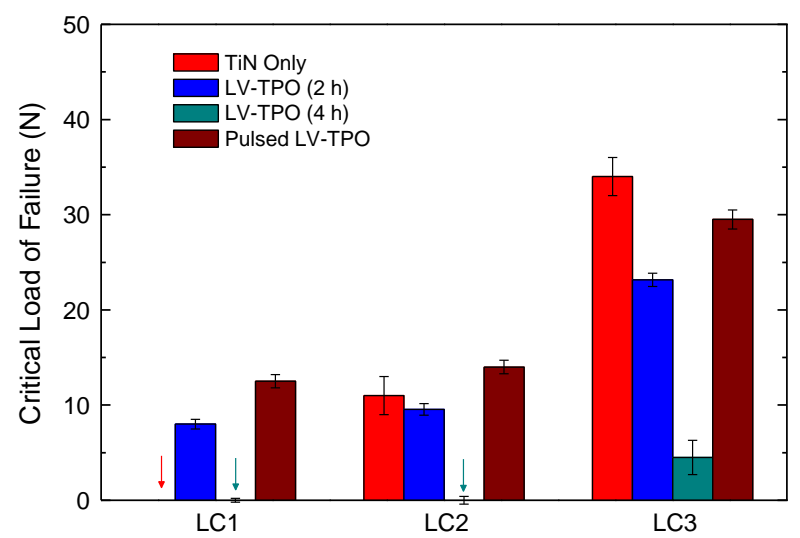

Fig. 4. Critical loads for failure of a $2.8 \mu \mathrm{m}$ TiN coating deposited on untreated and different pre-oxidised Ti-6Al-4V samples. All TPO processes were held at $700{ }^{\circ} \mathrm{C}$.

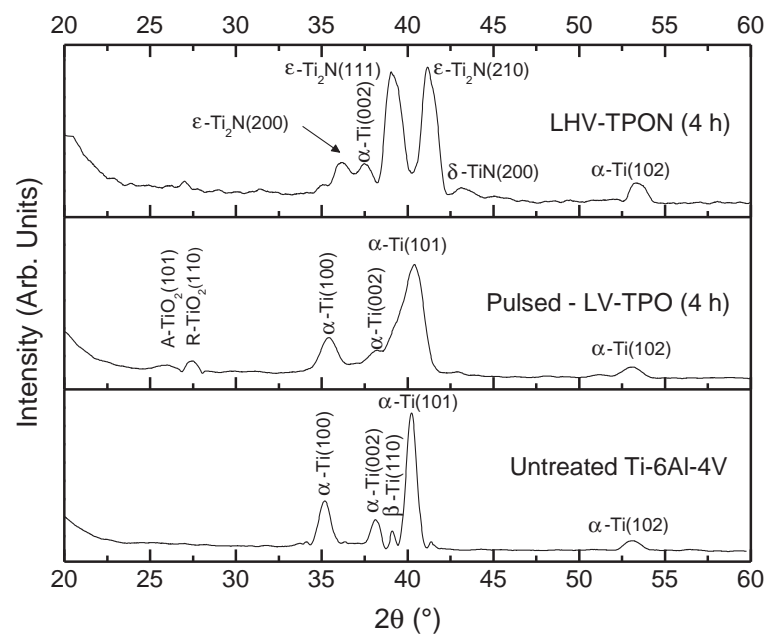

Fig. 5. GAXRD ( $2^{\circ}$ angle of incidence) diffractograms of untreated, pulse-oxidised and plasma oxynitrided Ti-6Al-4V samples (A: anatase, R: rutile).

Fig. 5 shows that practically no anatase or rutile $\mathrm{TiO}_{2}$ peaks appear, rendering an XRD pattern very similar to that of the untreated Ti-alloy material - with the exception of some peak shifting and broadening. The remaining thin layer of oxide was found to be relatively hard to remove and typically extended soaking in argon plasma was needed at the end of the process (say a further hour at high temperature), such that a completely clean surface was assured.

Pulsing the oxygen flow during the TPO process gives higher PVD coating cohesive and adhesive critical loads. Scratch-adhesion results in Fig. 4 show that this type of boost-diffuse cycle is able to provide an improved bond between the Ti surface and the coating compared to the non-duplex TiN sample. This is mostly due to the improved loadbearing capacity of the diffusion-treated substrate as its hardness is increased. For any given load the elastic-plastic deformation of the substrate-coating system will decrease and as the displaced material is reduced the stresses created by the differential recovery of the coating and substrate (in the wake of the indenter) also decrease $[25,26]$.

However, cross-sectional hardness profiles performed on pulsed TPO processes demonstrated that the efficiency of the TPO process was reduced considerably for the surface of Ti alloy to be sufficiently 'clean' for a PVD TiN ceramic coating to adhere. While TPO could indeed provide a suitable source of oxygen atoms for the subsequent diffusion stage, this oxide layer is not rapidly consumed during the diffusion part of the cycle. For this to be removed (and in order to minimise the total process duration), the oxidation stage duration and oxygen partial pressure were both reduced, such that the rate of oxide layer formation decreased accordingly. In this regard, around 30\% oxygen content $(70 \% \mathrm{Ar}$ ) and an oxidation stage of less than $40 \%$ of the total treatment time were found necessary, to sufficiently suppress oxide layer formation. Under these conditions the oxide layer was much thinner $(<0.1 \mu \mathrm{m})$ and any residue could be sputtered off before coating deposition. For such cyclic boost-diffuse processes, any improvement in adhesion is typically obtained at the expense of near-surface substrate hardening - compared to that achievable in a continuous diffusion process of the same duration.

The second technique studied aimed to remove any oxide compound layer from the surface of the TPO-treated Ti alloy and was a progression of the first technique described above. This method aided the consumption of the surface oxide by combining the final diffuse/sputter TPO treatment with a nitriding process. The TPO process hereby provides a large initial 'dose' of oxygen to the surface of the metal, while any oxide compound layer formed can be consumed during the subsequent TPN processes. Clearly, in comparison to the first technique, the advantages are numerous, since the 
TPN process maintains the high surface saturation level (and solute concentration gradient) in the metal throughout the entire process, while also potentially creating a nitride compound layer at the surface, which can be shown to be beneficial to the adhesion of PVD coatings. Furthermore, as demonstrated in Fig. 1, the introduction of a brief high-voltage stage to the end of the process was also found to aid in increasing the generation of nitrides. A final HV-nitriding step can ensure that the chemical composition of a triode-plasma oxidised and nitrided (TPON) surface is practically identical to that of a purely nitrided sample. The XRD pattern in Fig. 5 shows the phase composition of the surface of a sample treated with this three-stage LHV-TPON process. In this case, no oxide reflections are observable while $\mathrm{Ti}_{2} \mathrm{~N}$ and TiN phases clearly emerged.

The introduction of $1 \mathrm{~h}$ of nitriding at a high negative bias voltage in the later stage of LHV-TPN does not measurably improve the overall hardness-depth profile in the treated Ti-alloy substrate. Nevertheless, this contributes to an increased near-surface hardening by promoting nitride compound-layer formation. The low-pressure intensified glow discharge used for nitriding permits the arrival of very high numbers of energetic ionised species carrying almost the full cathode fall potential $[9,11,21]$. Nanoindentation showed a small increase in surface hardness from $~ 9.3 \mathrm{GPa}$ in LV-TPN to $10.2 \mathrm{GPa}$ in LHV-TPN but, more importantly, this final hour of high-voltage nitriding can be correlated to an improved coating adhesion, as demonstrated below.

Fig. 6a shows hardness-depth profile plots for the 'improved' diffusion treatments compared to baseline LV-TPN. This figure shows the increased hardening response obtained down to a depth of around $60 \mu \mathrm{m}$ when using TPON processes, while Fig. 6b illustrates the compositional profile of TPON-treated Ti-6Al-4V. The GDOES plot shows how the oxygen distribution was changed (from that presented for the LV-TPO process in Fig. 2) due to the reduced oxidation stage duration and the subsequent $3 \mathrm{~h}$ of nitriding used in LV-TPON. Particularly, the surface oxygen content is visibly reduced, while further investigation using GDOES has shown no significant oxygen presence at the surface ( $<3 \mu \mathrm{m}$ depth) when employing a high voltage nitriding step i.e. in LHV-type treatments.

Scratch testing was used to observe and quantify the improvement in adhesion strength provided by the LV and HV-TPN stages of the process, introduced following the initial TPO stage. Comparing the results in Fig. 4 with those for a single-layered TiN sample (Fig. 7) shows how the triode plasma diffusion treatment plays a vital role in improving the load-bearing capability of the substrate for the ceramic

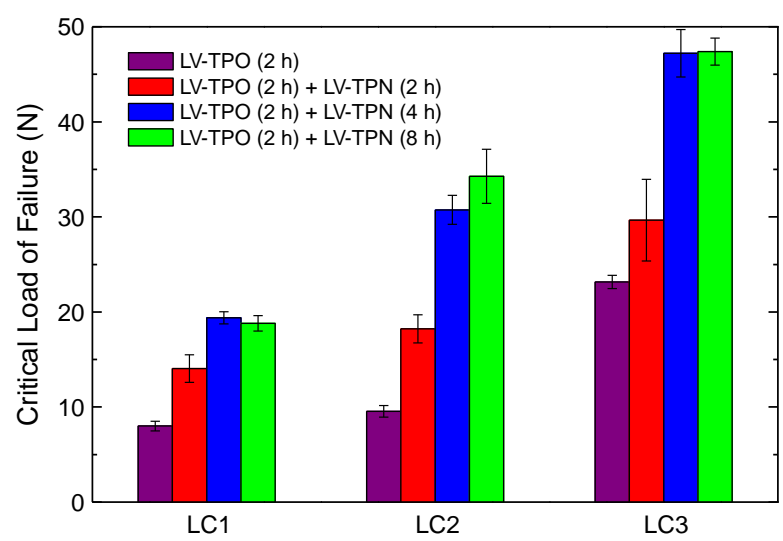

Fig. 7. Critical loads for failure of a $2.8 \mu \mathrm{m}$ TiN coating deposited on LV-TPO and LVTPON treated Ti-6Al-4V. Samples were oxidised for $2 \mathrm{~h}$ and subsequently nitrided for increasing amounts of time.

PVD coating and, consequently, the scratch resistance of the duplex treatment is much higher. However, this only becomes truly evident when the compatibility of the surface chemistry is optimised. The critical loads presented in Fig. 7 for duplex-treated samples show a higher cohesive and adhesive strength in the coating with increasing nitriding duration, particularly when the TPN process duration is double or more than that of the TPO stage. This difference is more pronounced in $L_{\mathrm{C} 2}$ and $L_{\mathrm{C} 3}$ values, since these are a better measure of adhesion strength at the interface - while $L_{C 1}$ gives a qualitative indication of the toughness of the film [27]. Also, for longer TPN processes (exceeding $4 \mathrm{~h}$ ), the improvement is less marked. This can be attributed to two factors: (i) the surface becomes entirely composed of nitrides and the continued increase in $L_{C}$ values is not related to surface chemistry but to the elastic-plastic deformation behaviour of the substrate; in turn this is predominantly controlled by the diffusion zone depth beneath the surface compound layer - the rate of growth of which reduces with time. (ii) Longer TPN process times increase the surface roughness of the sample [22]; an increased surface roughness has also been associated with the presence of larger number of interfacial flaws (which can lead to coating spallation $[28,29])$, while surface asperities cause localised stress concentrations and create large delamination sites (which lead to a considerable reduction in critical load [30,31]).

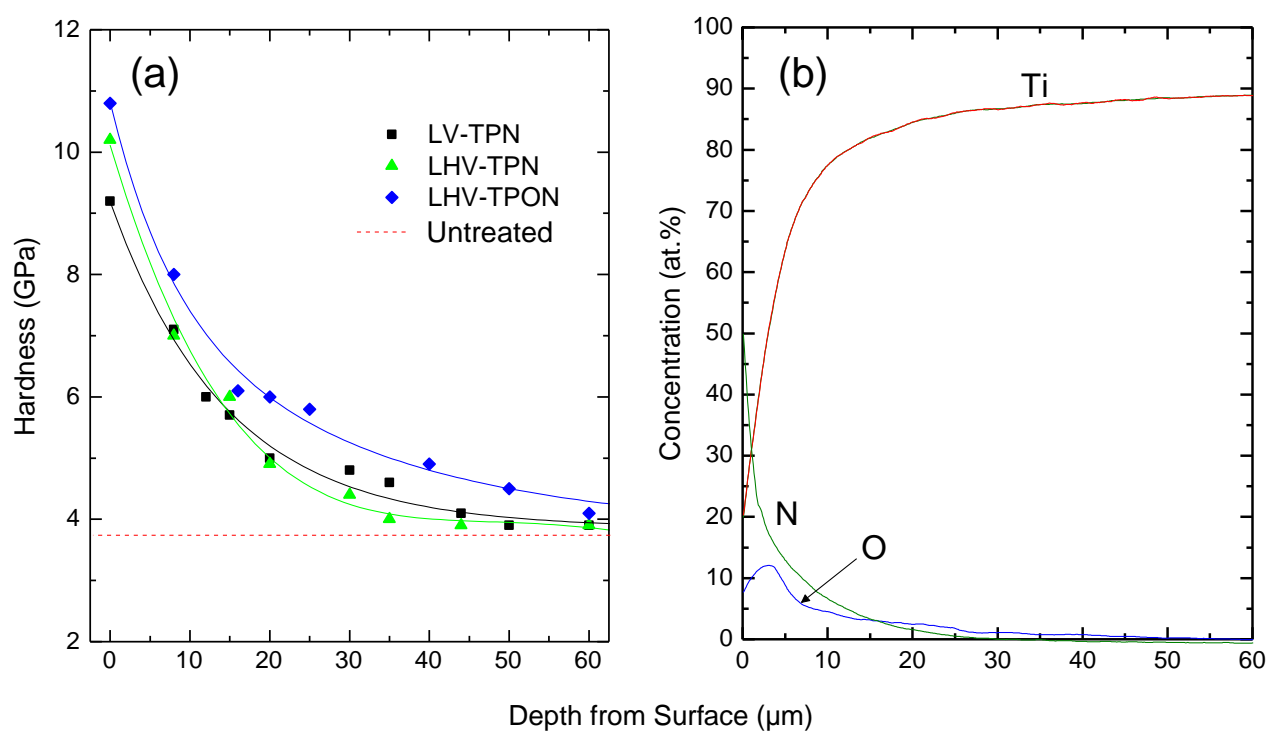

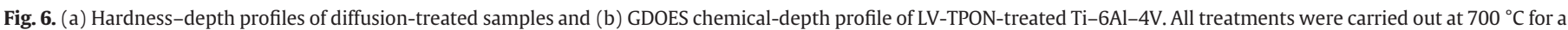
total of $4 \mathrm{~h}$. Scan lines for $\mathrm{Al}, \mathrm{V}$ and impurities are excluded, for clarity. 
Fig. 8 shows how the improvement in PVD coating adhesion and increased load-bearing capacity also lead to a change in failure characteristics. The images show that the position at which the TiN layer starts to be removed from the edge of the wear scar moves further away from the position where the test was initiated (i.e. to higher indentation loads) when the 2 h oxidation stage is followed by a nitriding stage of increasing duration. With increasing diffusion treatment time, the TiN coating shows progressively better resistance to the bending stresses generated along the wear scar (by the material being pushed outside the track) without debonding from the underlying material. The brittle failure of the coating is contained closer to the scratch track and the failure mode becomes similar to what is typically described as ductile failure [32]. In fact, ductile failures are associated with much higher critical loads. Semicircular tensile cracks could also be observed for all duplex coatings and the critical load at which tensile cracks started to form was taken as the critical load for cohesive failure $\left(L_{C 1}\right)$. A harder substrate can mitigate tensile stresses by reducing the radius of curvature of the deformed coating (i.e. less material pile-up), which can be shown to be proportional to the critical load [31]. Fig. 9 shows 2D and 3D maps of scratch tracks for TiN-coated and duplex diffusion-treated/coated samples; and these demonstrate how the triode plasma diffusion process acts to reduce the material pushed perpendicularly to the side of the scar, thereby lowering the bending stresses generated. Typically, for coatings which were deposited on samples offering poor load-bearing capacity, tensile cracks were soon followed by local adhesive failures at the centre of the scar; while for samples which provided good mechanical support to the coating, the first occurrence of adhesive failure was in the form of edge chipping. The effect of these treatments on chemical and mechanical compatibility is synergistic. In fact, similar failures may often be observed in both nitrided-only surfaces (due to an insufficient case depth) and oxidised samples (due to residual oxide on the surface, resulting in poor coating adhesion).

It is also instructive to compare samples which had equal total process durations. Fig. 10 compares $L_{C}$ values for the TPON samples (shown in previous figures) with equivalent TPN treatments carried out for the same total duration. The figure reiterates that the nitriding treatment following a TPO cycle has to be substantially longer. In fact, samples treated only with a nitrogen plasma reach higher $L_{C}$ values, suggesting an incomplete conversion of the surface oxide in TPON. In other words, although the depth of substrate hardening is significantly higher for the TPON samples, the surface has still not achieved its maximum potential for PVD coating adhesion, compared to a simple TPN hardening process. It is obviously difficult to separate the effect on $L_{C}$ values caused by a change in case depth and that caused by a change in surface composition, since the different treatment
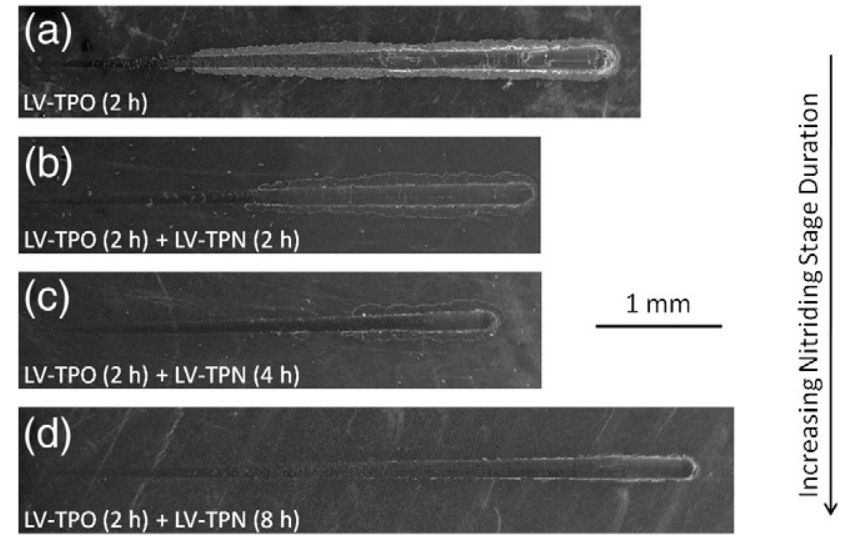

Fig. 8. SEM micrographs of scratch tracks for duplex TiN-coated samples previously subjected to (a) LV-TPO (2 h), and (b), (c) and (d) LV-TPO ( 2 h) followed by 2, 4 and $8 \mathrm{~h}$ LV-TPN respectively. processes lead to simultaneous modification of both. However, it can be seen that, as the surface oxide is consumed during subsequent nitriding, the degree of substrate hardening and load-support becomes increasingly important. For instance, the $L_{C}$ values of a TPON process composed of a $2 \mathrm{~h} \mathrm{TPO}$ and a $4 \mathrm{~h}$ TPN process (Fig. 7) are significantly higher than those of an $8 \mathrm{~h}$ TPN process (Fig. 10), demonstrating that the deeper case depth ( $25 \%$ thicker - despite the $25 \%$ shorter overall treatment time) of the former is the primary reason for this improvement.

It is clear that, although oxygen serves to generate a deeper surface hardening treatment than nitrogen (for a given treatment time), it also calls for greater attention to avoid possible adhesion problems for any subsequent PVD coating treatment. The use of nitriding to convert the surface of pre-oxidised samples to one more chemically suitable for PVD coating appears to be a potential solution to this problem; however, an extended nitriding process may be required, possibly several times longer than the TPO cycle duration. In order to reduce the overall duration of such a TPON process, the nitriding treatment was modified to include $1 \mathrm{~h}$ at a negative cathode bias of $1000 \mathrm{~V}$. As demonstrated earlier, a short high voltage nitriding phase at the end of the treatment promotes rapid nitride compound formation, forming a harder near surface region (closer to that of a PVD layer) while removing residual oxides. In this respect, several observations can be made by comparing two otherwise identical treatments except for the final hour of treatment held at a higher cathode voltage shown in Fig. 11. Comparing the $4 \mathrm{~h}$ LHV-TPN process to $4 \mathrm{~h}$ LV-TPN shows that an increased voltage for the final hour of the process increases the resulting $L_{C 3}$ value of TiN coating by around $40 \%$. Furthermore, the effect of increased load-support from an initial oxidising stage is again apparent, as the scratch test critical load values for LV-TPO + LHVTPN treated samples reach high magnitudes more typically associated with CVD and PVD coating of tool steels intended for high performance machining [33].

Comparing the scratch adhesion results for samples treated with LHV-TPON for a total of $8 \mathrm{~h}$ (Fig. 11) with other $8 \mathrm{~h}$ processes (Fig. 10), it also becomes clear that the addition of a $1 \mathrm{~h}$ final nitriding stage at high negative voltage drastically reduces the nitriding time necessary to achieve satisfactory PVD coating adhesion. Indeed, the $L_{C}$ values obtained in this case are still higher than those obtained after much longer processes, such as a $4 \mathrm{~h}$ TPO process followed by $8 \mathrm{~h}$ of LV-TPN. Thus, with the introduction of this small (but significant) process modification, the same adhesion strength can be obtained in substantially less processing time that would otherwise be required. Also, no sign of gross coating delamination could be observed, evidence of the fact that any oxide compound layer generated by a $4 \mathrm{~h}$ TPO process can be removed in only $4 \mathrm{~h}$ of plasma nitriding - if the latter includes a HV stage in the final hour of treatment.

Similar scratch test evaluations were conducted on triode plasma diffusion-treated samples coated with CrAlN. Scratch tests do not simply assess the adhesive strength of coatings at the interface but, due to the complex stress states involved in this short-time tribological test, the cohesive strength of the surface layer is also investigated. Therefore, the properties of the coating play a major role in the results observed. Thus, it is interesting to note that substantially higher $L_{C 1}$ and $L_{C 2}$ values are measured for CrAlN (Fig. 12) compared to TiN (Fig. 6) when deposited on untreated Ti-6Al-4V substrates. This can be related to the intrinsically superior mechanical properties of CrAlN compared to TiN. Firstly, assuming a Poisson's ratio of 0.25 for CrAlN [34] and 0.22 for TiN [35,36], the elastic moduli can be calculated from nanoindentation data to be approximately $364 \mathrm{GPa}$ and $466 \mathrm{GPa}$, respectively. This difference clearly changes the elasticplastic deformation behaviour of the coatings during scratching and the lower Young's modulus of CrAlN clearly allows it to better adapt to the deformation of the substrate without cracking or spalling. Similarly, the higher hardness of CrAlN (32.1 GPa) compared to that of TiN (26.2 GPa) hinders penetration of the indenter and limits 

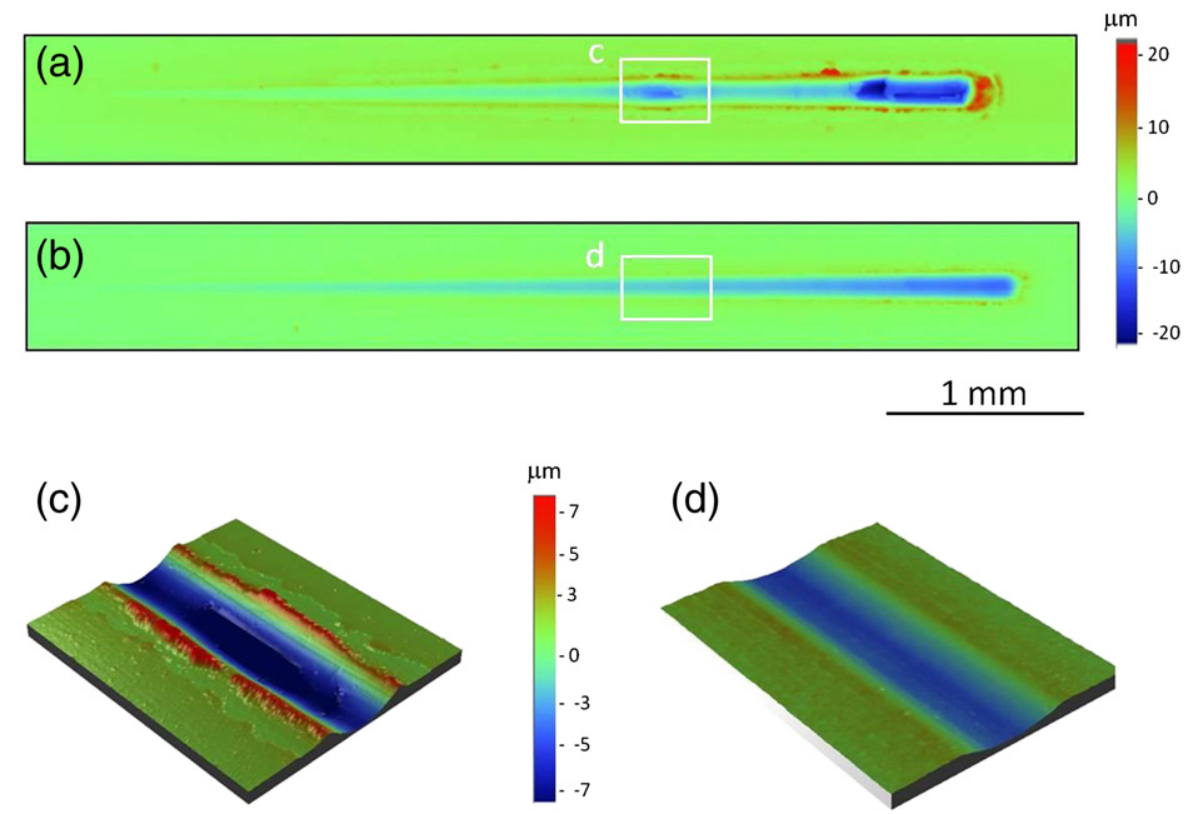

Fig. 9. Stereometric images of scratch tracks for TiN-coated samples: (a) and (c) single-layered; (b) and (d) duplex treated/coated.

plastic flow (promoting elastic deformation) of the coating, reducing surface crack formation. Finally, the differences in adhesion strength between the two coatings could potentially be correlated to the difference in nominal coating thickness between the two (CrAlN being thinner). However, controversy still exists over the effect of film thickness on the critical loads measured using scratch testing. On the one hand, several authors have shown that the critical load for coating delamination increases with thickness [37-39], while others attributed the accumulation of strain energy in the film (due to frictional stress, elastic-plastic indentation stress and internal residual stress) to increased spalling for thicker coatings $[30,35,40]$. Furthermore, the relatively soft Ti substrate used here dictates that the frictional energy component is the dominating factor of the total energy in the coating and therefore a greater coating thickness (which tends to increase the internal and indentation stress but reduces the frictional energy) should permit higher $L_{C}$ values $[40,41]$. In order to ascertain whether the minor differences in nominal coating thickness affected the results presented here, repeated testing was performed on samples coated with CrAlN layers of varying thickness, in the range of $1.6 \mu \mathrm{m}$ to $3.9 \mu \mathrm{m}$. The resultant $L_{C}$ values were found to vary by less than $\pm 10 \%$. Clearly therefore, despite the slightly different thicknesses, comparing the scratch-adhesion performance of the TiN $(2.8 \mu \mathrm{m})$ and $\mathrm{CrAlN}$ $(2 \mu \mathrm{m})$ PVD coatings reported here is still valid.

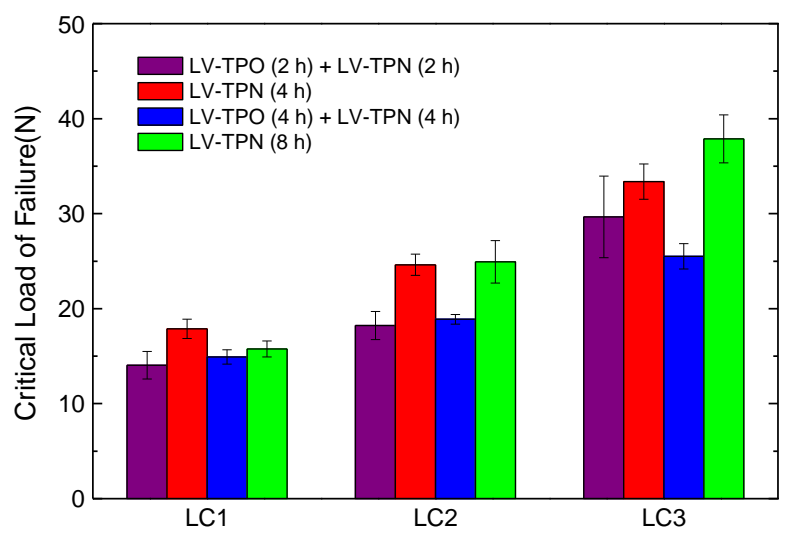

Fig. 10. Critical loads for failure of a $2.8 \mu \mathrm{m}$ TiN coating deposited on LV-TPN and LVTPON treated Ti-6Al-4V.
The superiority of CrAlN is also evident when deposited on a diffusion-treated substrate. Fig. 12 shows the scratch test results for duplex diffusion-treated and CrAlN-coated samples. Once again the benefits of substrate plasma diffusion pre-treatment, in terms of improving the load-bearing capacity for duplex PVD coating, can be seen from the higher critical loads achieved with the various duplextreated samples compared to the single-layered sample. Comparing the results shown in this figure to those presented earlier in Fig. 11 shows that the critical load values of CrAlN are higher still than those measured for the thicker TiN when deposited on an identical pretreated $\mathrm{Ti}-6 \mathrm{Al}-4 \mathrm{~V}$ substrate. The mean load necessary to initiate cohesive failure was found to be $\sim 37 \%$ higher for CrAlN when used together with a diffusion-treatment, while an increase of $~ 30 \%$ was measured in the adhesive failure load.

Also, the micrographs shown in Fig. 13 suggest that the failure mode in scratch testing for the two PVD coatings is markedly different. In duplex TiN, a propensity for increased longitudinal cracking with load can be observed along the scratch length (Fig. 13a) until severe (and continuous) flaking is initiated along the edges of the scratch. As the indenter ploughs into the surface, material is extruded laterally and eventually, when the coating is unable to endure the bending stress generated in the direction perpendicular to

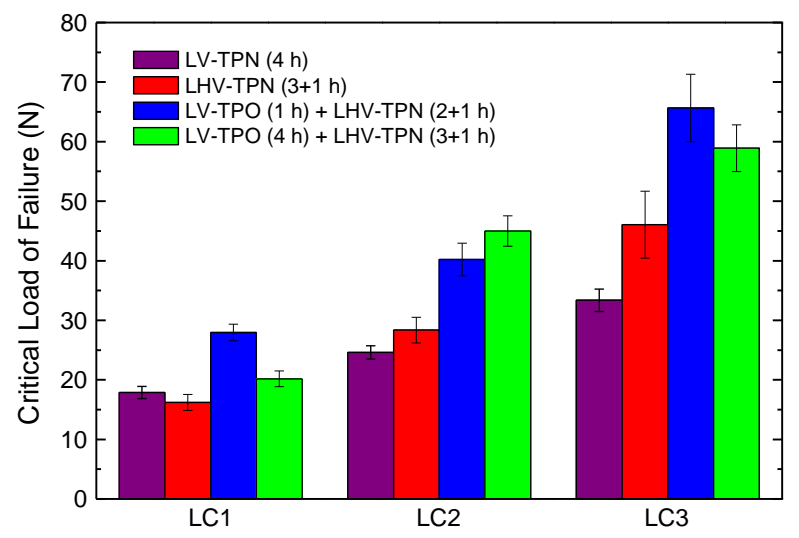

Fig. 11. Critical loads for failure of a $2.8 \mu \mathrm{m}$ TiN coating deposited on LV-TPN, LHV-TPN and LHV-TPON treated Ti-6Al-4V. The TPN phase of LHV samples included nitriding for $1 \mathrm{~h}$ at $-1000 \mathrm{~V}$. 


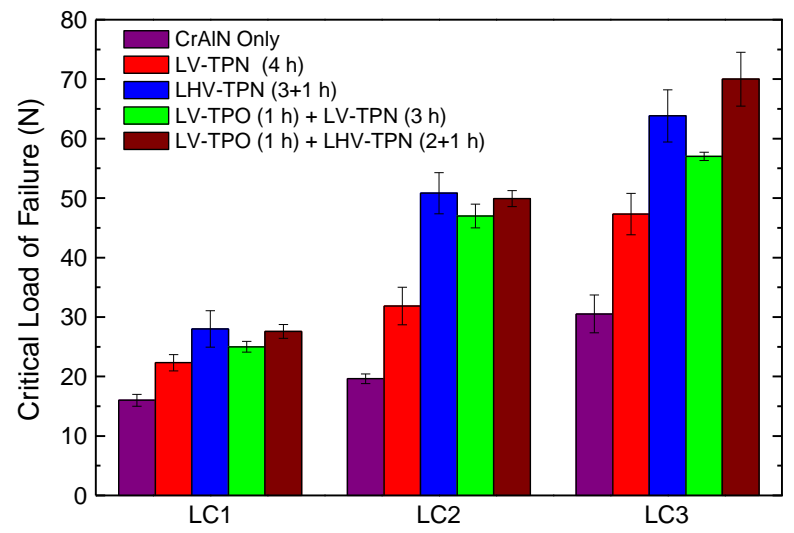

Fig. 12. Critical loads for failure of a $2 \mu \mathrm{m}$ CrAlN coating deposited on various untreated, TPN and TPON treated Ti-6Al-4V. The TPN phase of the LHV-TPON process included $1 \mathrm{~h}$ at a cathode bias of $-1000 \mathrm{~V}$.

the scratch direction, adhesive failure occurs [42]. For compliant materials like $\mathrm{Ti}$, this bending-induced stress may be very significant as the amount of material displaced from the bottom of the groove to its side can be considerable.

Compared to single-layered CrAlN (Fig. 13b), duplex LHV-TPON+ CrAlN shows almost no sign of edge chipping (spallation along the scratch borders) until the load is increased sufficiently that this effect appears together with large scale buckling spallation (Fig. 13c). This mode of failure occurs in response to compressive stresses generated ahead of the moving indenter (where material is detached), to minimise the stored elastic energy [43]. Once film buckling occurs (at a local defect) the stylus passes over this failed region and crushes the coating into the surface [44]. Then individual buckle failures, at the centre of the scratch, spread laterally. Compared to single-layered CrAlN the development of buckle failures appears at around double the indenter travel for duplex LHV-TPON + CrAIN (Fig. 13b and c), demonstrating the beneficial effect of the TPON diffusion treatment (and resultant reduced plastic deformation) immediately below the coating. Buckle failures increase in size and frequency along the scar until the coating is completely stripped off (Fig. 13d and e) and the Ti-alloy substrate is exposed.

Also, underlying the main failure modes described above, both coatings also exhibit brittle tensile cracking, curved towards the starting end of the scratch (Fig. 13a and c). These tensile cracks appear first (at relatively low loads) and thus their onset marks $L_{C 1}$. Both these and the longitudinal cracking are caused by tensile stresses generated in the wake of the indenter as the coating attempts to partly relieve this stress.

\subsection{Wear testing}

Fig. 14 illustrates the results of reciprocating-sliding ball-on-plate wear tests for several treatments of interest. All duplex-treated/coated samples provide a large improvement in wear resistance under reciprocating-sliding wear testing compared to the untreated alloy. The figure also clearly shows that, for TiN-coated samples, modification of the benchmark LV-TPN diffusion process leads to a direct increase in the wear life of the coated surface. Perforation of TiN-coated LV-TPNtreated samples occurred at around $200 \mathrm{~m}$, while TiN-coated LHVTPON-treated samples survived up to a sliding distance of around $800 \mathrm{~m}$. This can be related to two principal factors. Firstly, the increased substrate load-support to the ceramic coating, which reduces surface
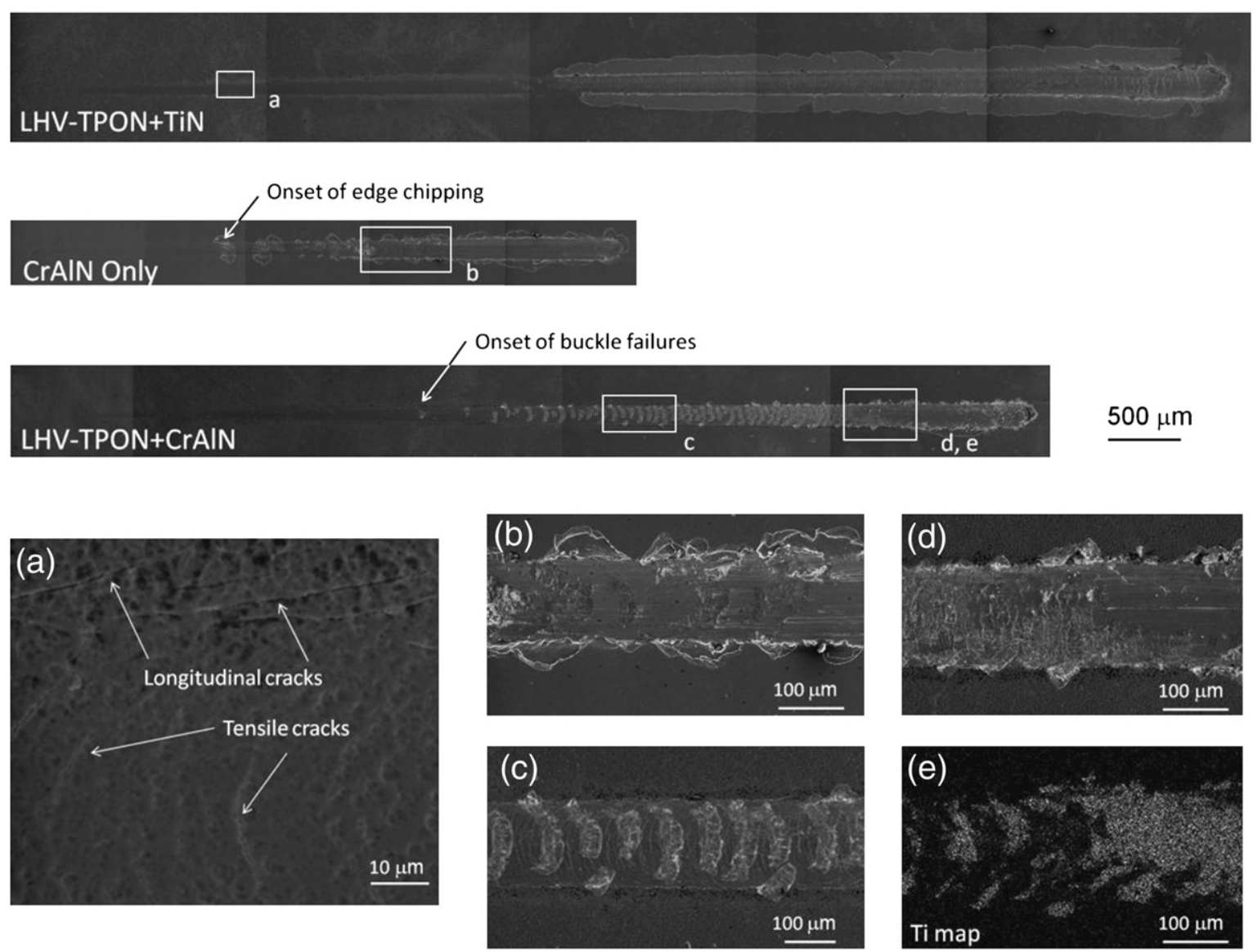

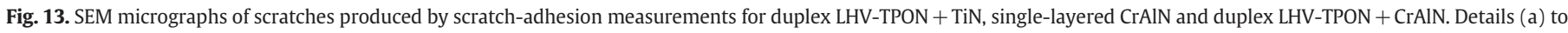

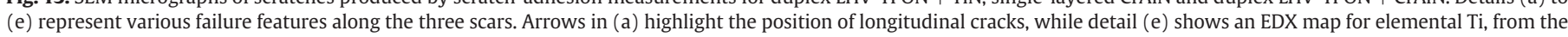
substrate being exposed. 


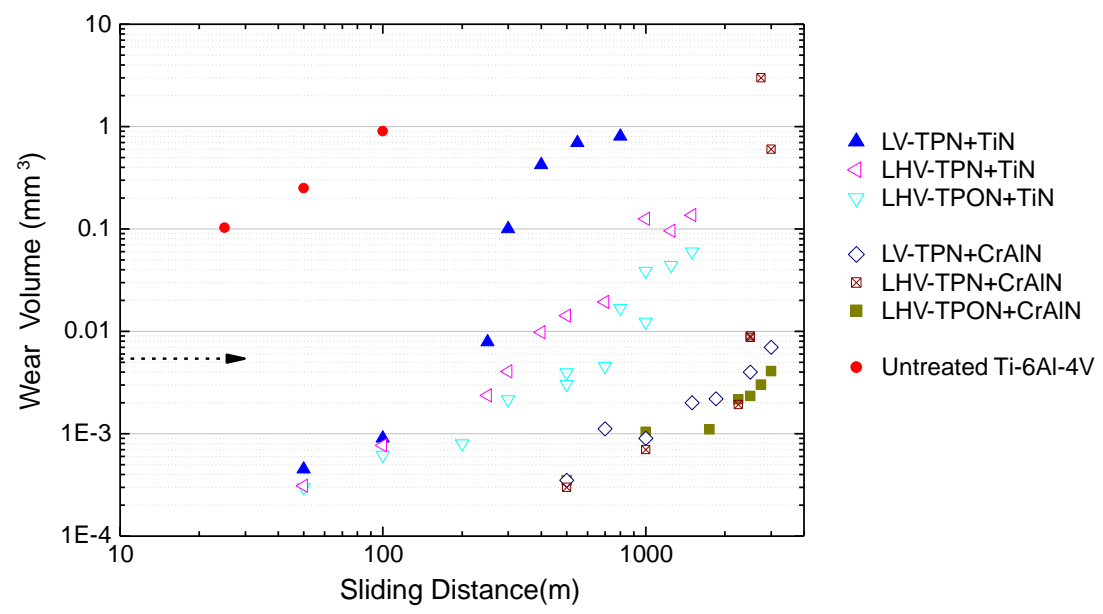

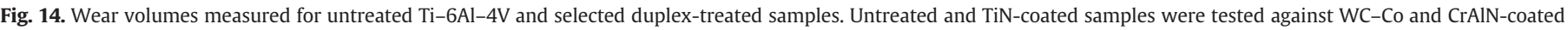

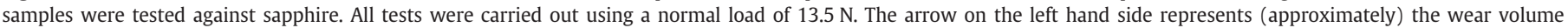
equivalent to a scar depth of $2 \mu \mathrm{m}$ i.e. the ball has penetrated through the coating.

strains under load and avoids premature cohesive failure. The increased efficacy of the TPON process in diffusing interstitial solute atoms to create a deeper hardened case (at a given treatment time and temperature) has already been demonstrated. Secondly, the HV-phase of the treatment has been shown to improve the adhesion of the TiN layer, thereby reducing the likelihood of adhesive failure. Clearly, changes in the process routine - whilst maintaining the same process duration and temperature - can result in a large reduction in dry sliding wear. In comparison, single-layered TiN when tested under identical conditions reaches a similar level of wear damage after only $12 \mathrm{~m}$ of sliding distance.

Further work was carried out to assess the relative contribution of the two dominant factors explained above (i.e. adhesion and loadsupport). Eight-hour LV-TPN and LV-TPON diffusion treatments (the latter including a $4 \mathrm{~h}$ LV-TPO phase) were carried out on Ti-6Al-4V and these were subsequently coated. The longer treatment duration allowed for a better analysis of the efficacy of the two treatments. The adhesion strength of these samples is illustrated in Fig. 10 and, in terms of critical loads, was found to be superior in the case of the LVTPN sample; nevertheless, reciprocating ball-on-plate tests show a significantly higher wear resistance of the TPON-treated samples which had been oxidised and subsequently nitrided (Fig. 15), suggesting that the provision of improved load-support to the coating is more important than higher adhesion strength. Furthermore, this suggests that an adhesion strength as low as $30 \mathrm{~N}$ can be sufficient to attain satisfactory coating performance, if the underlying substrate load support is optimised.

CrAlN-coated samples also exhibit an increased resistance to dry sliding wear; because of the tribological superiority of CrAlN compared to TiN [22]; all points in Fig. 14 are shifted to the higher end of test sliding distances for the former. The contact loads required to induce plastic deformation in CrAlN are higher due to its combination of high hardness, $H$, and low (compared to many PVD coatings) elastic modulus, E. Several authors have verified a direct correlation between coating performance and the $H / E$ ratio [45-47] (or the $H^{3} / E^{2}$ ratio $[48,49]$ - which is said to be indicative of coating resistance to plastic yielding under load) across a variety of different tribological tests. In this work, the $\mathrm{H}^{3} / E^{2}$ yield pressure parameter equates to 0.28 for CrAIN and 0.08 for TiN. The consequently higher resistance to yielding of the CrAlN film is a major contributory factor to its remarkable performance. Furthermore, Fig. 14 shows that LHV-TPON can further increase the wear resistance of CrAIN by lengthening the period in which the coating remains intact, albeit the improvement is less pronounced than in the case of TiN-coated samples (Fig. 15). Interestingly, duplex-treated LHV-TPN + CrAlN samples show some relatively early failures at sliding distances approaching $2500 \mathrm{~m}$. This suggests that, in the case of very hard coatings such as CrAlN, the increase in surface hardness is less important than the overall increase in diffusion-hardened case depth. This is in agreement with the scratch-

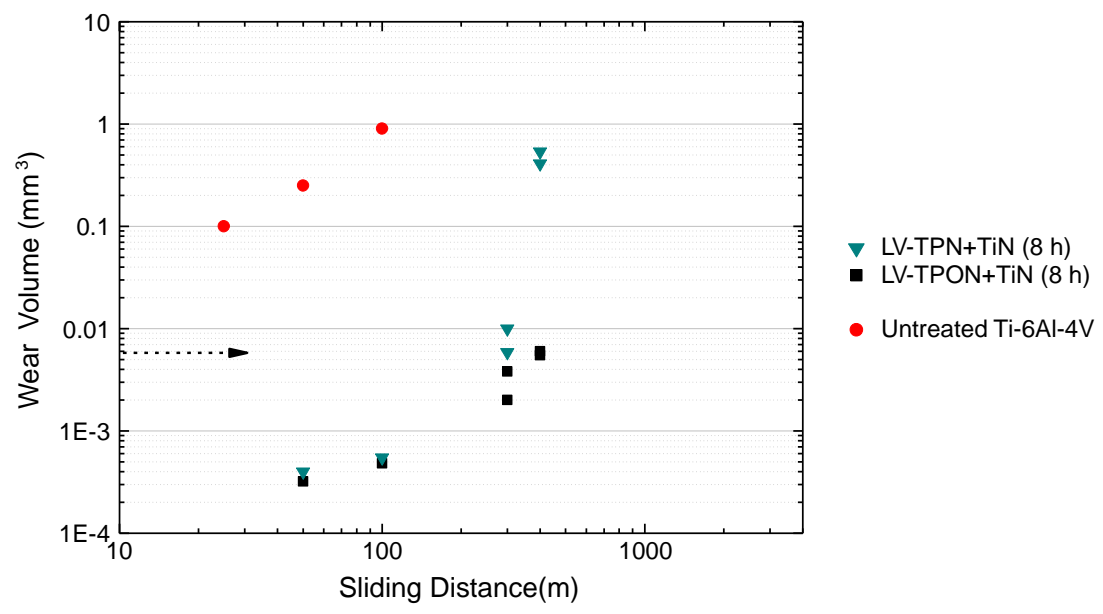

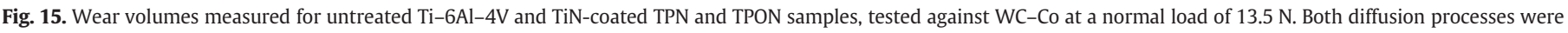

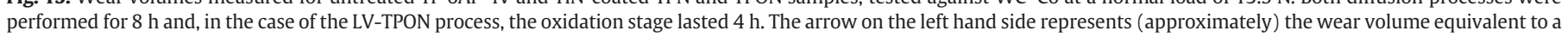
scar depth of $2 \mu \mathrm{m}$ i.e. the ball has penetrated through the coating. 
adhesion test data presented for CrAlN-coated samples in Fig. 12, whereby the addition of an oxidation phase to the treatment was also shown to increase the resistance to adhesive failure against the sliding scratch indenter. Overall, if the load-carrying capacity is defined as the ability of a system to bear normal and tangential forces applied to the surface without loss of functionality, then clearly the modified diffusion treatments reported here are capable of providing a large improvement in this regard.

\section{Conclusions}

The adhesion of PVD TiN and CrAlN coatings was measured using scratch testing and correlations between triode plasma diffusion treatment regime and coating adhesion were made. It can be seen that duplex diffusion/coating treatments exhibit higher critical loads than their non-duplex counterparts. This has been shown to relate to improvements in load-bearing capacity and chemical affinity between the coatings and diffusion-treated surfaces.

Particular attention was given to the use of oxidation treatments which are known to be capable of providing superior case depth to nitriding. TPO-type treatments were found to be largely deleterious to the adhesion of PVD coatings; however, the introduction of a nitriding stage following the initial oxidation phase can improve substantially coating adhesion. The duration of the nitriding stage typically needs to be at least twice that of the preceding oxidation phase, in order to remove all traces of oxide compound layer. Following such LV-TPON processes, $L_{C 2}$ and $L_{C 3}$ values were well in excess of $40 \mathrm{~N}$ and $55 \mathrm{~N}$ respectively. These values are typically considered to be acceptable for PVD coatings on tool steel substrates [33,50]; thus, as a benchmark, obtaining similar values on Ti-alloy substrates was considered essential for achieving competitive tribological performance (from a light-alloy component). In addition, a further modification of the process (to include a final short nitriding stage at higher substrate negative bias) was found to be particularly beneficial to coating adhesion and this was correlated to accelerated nitride compound layer growth at the high substrate bias applied. Increasing the cathode bias voltage from $-200 \mathrm{~V}$ to $-1000 \mathrm{~V}$ for the last hour of the TPN phase significantly reduces the nitriding stage duration required for oxide layer removal, in turn allowing for a longer TPO phase during which advantage is taken of the higher diffusion coefficient of oxygen compared to that of nitrogen (at the given treatment temperature). This allows a deeper hardened case to be obtained in shorter treatment times without loss in adhesion strength of the subsequently deposited PVD coating.

The improved adhesion and load-support affected the failure mode of the two coatings studied in this work. Extensive coating spallation outside the scratch track was eliminated and buckling crack formation (at substantially higher scratch loads) was favoured for coatings deposited on properly diffusion-pretreated samples. Compared to TiN, CrAlN showed superior resistance to the applied loading regime and no longitudinal cracking was observed outside the scratch track. This was correlated to differences in coating mechanical properties (particularly elastic modulus).

Reciprocating-sliding wear testing of oxidised and subsequently nitrided samples showed a large improvement in the tribological characteristics of the titanium alloy following this treatment. Clearly, careful process design can considerably improve the treatment efficacy, without necessitating higher treatment temperatures and/or longer process durations. Therefore, for applications involving very high contact loads duplex TPON/PVD diffusion/coating processes (especially in conjunction with a final HV-TPN phase) are recommended.

\section{Acknowledgements}

The authors gratefully acknowledge financial support from the UK Technology Strategy Board under Technology Programme project $\mathrm{TP} / 22076$, for underpinning research carried out at Sheffield University, on which the work presented in this paper was partially based.

\section{References}

[1] K. Miyoshi, D. Buckley, NASA TP-1883, 1981, p. 1.

[2] T. Wierzchon, A. Fleszar, Surf. Coat. Technol. 96 (1997) 205.

[3] U. Wiklund, I.M. Hutchings, Wear 251 (2001) 1034.

[4] Y. Fu, N.L. Loh, A.W. Batchelor, D. Liu, X. Zhu, J. He, K. Xu, Surf. Coat. Technol. 106 (1998) 193.

[5] ASM Handbook, Volume 18: Friction, Lubrication and Wear Technology, ASM International, 1992, p. 1102.

[6] K. Miyoshi, International Tribology Conference, Yokohama, Japan 290ct - 2Nov, NASA TM-106815, , 1995, p. 1.

[7] I.D. Radomysel'skii, N.N. Manukyan, Powder Metall. Met. C 23 (1) (1984) 76.

[8] J. Meneve, K. Vercammen, E. Dekempeneer, J. Smeets, Surf. Coat. Technol. 94-95 (1997) 476.

[9] A. Leyland, K.S. Fancey, A. Matthews, Surf. Eng. 7 (3) (1991) 207.

[10] A. Matthews, A. Leyland, Surf. Coat. Technol. 71 (1995) 88.

[11] A. Leyland, K.S. Fancey, A.S. James, A. Matthews, Surf. Coat. Technol. 41 (1990) 295.

[12] BS EN ISO 4545-1, Metallic materials - Knoop hardness test - Part 1: Test Method, 2005, p. $1, \mathrm{BSi}$.

[13] BS EN 1071-3, Advanced Technical Ceramics - Methods of Test for Ceramic Coatings - Part 3, 2005, p. 1, BSi.

[14] A. Zhecheva, W. Sha, S. Malinov, Surf. Coat. Technol. 200 (2005) 2192

[15] C. Braganza, H. Stüssi, S. Veprek, J. Nucl. Mater. 87 (1979) 331.

[16] V. Fouquet, L. Pichon, M. Drouet, A. Straboni, Appl. Surf. Sci. 221 (2004) 248

[17] E.I. Meletis, C.V. Cooper, K. Marchev, Surf. Coat. Technol. 113 (1999) 201.

[18] E. Metin, O.T. Inal, Metall. Trans. A 20 (A) (1989) 1819.

[19] S. Taktak, H. Akbulut, Vacuum 75 (2004) 247.

[20] F.W. Wood, O.G. Paasche, Thin Solid Films 40 (1977) 131

[21] N. Kashaev, H.-R. Stock, P. Mayr, Met. Sci. Heat Treat. 46 (7-8) (2004) 294.

[22] G. Cassar, J.C. Avelar-Batista Wilson, S. Banfield, J. Housden, A. Matthews, A. Leyland, Wear 269 (2010) 60.

[23] J. Unnam, R.N. Shenoy, R.K. Clark, Oxid. Met. 26 (3/4) (1986) 231.

[24] H. Dong, X.Y. Li, Mat. Sci. Eng. A. Struct. 280 (2000) 303.

[25] A. Rodrigo, P. Perillo, H. Ichimura, Surf. Coat. Technol. 124 (2000) 87.

[26] J.C. Knight, T.F. Page, I.M. Hutchings, Thin Solid Films 177 (1989) 117.

[27] W. Pan, G. Yu, J. Huang, Surf. Coat. Technol. 110 (1998) 111.

[28] P.A. Steinmann, Y. Tardy, H.E. Hintermann, Thin Solid Films 154 (1987) 333.

[29] S.J. Bull, D.S. Rickerby, Surf. Coat. Technol. 42 (1990) 149

[30] J. Takadoum, H. Houmid Bennani, Surf. Coat. Technol. 96 (1997) 272.

[31] S.J. Bull, E.G. Berasetegui, Tribol. Int. 39 (2006) 99.

[32] S.J. Bull, Surf. Coat. Technol. 50 (1991) 25

[33] Handbook of Hard Coatings; Deposition Technologies, Properties and Applications, F. Bunshah (Ed.), William Andrew, New York, 2001, pp. 8-9, 112-113.

[34] J. Lin, B. Mishra, J.J. Moore, W.D. Sproul, Surf. Coat. Technol. 202 (2008) 3272.

[35] J. Valli, U. Mäkelä, A. Matthews, Surf. Eng. 2 (1) (1986) 49.

[36] M.T. Laugier, J. Mater. Sci. Lett. 2 (1983) 419.

[37] G. Berg, C. Friedrich, E. Broszeit, C. Berger, Fresen. J. Anal. Chem. 358 (1997) 281

[38] P.J. Burnett, D.S. Rickerby, Thin Solid Films 157 (1988) 233

[39] B. Hammer, A.J. Perry, P. Laeng, P.A. Steinmann, Thin Solid Films 96 (1982) 45.

[40] K.L. Mittal, Adhesion Measurement of Films and Coatings, VSP BV, 1995, p. 181.

[41] S.J. Bull, D.S. Rickerby, A. Matthews, A. Leyland, A.R. Pace, J. Valli, Surf. Coat. Technol. 36 (1988) 503.

[42] Y. Xie, H.M. Hawthorne, Surf. Coat. Technol. 155 (2002) 121.

[43] J. Li, W. Beres, Wear 260 (2006) 1232.

[44] S.J. Bull, Tribol. Int. 30 (7) (1997) 491.

[45] A. Leyland, A. Matthews, Wear 246 (2000) 1.

[46] T.Y. Tsui, G.M. Pharr, W.C. Oliver, Y.W. Chung, E.C. Cutiongco, C.S. Bhatia, R.L. White, R.L. Rhodes, S.M. Gorbatkin, MRS, Boston, 1995 pp. 1-6.

[47] J.C.A. Batista, C. Godoy, G. Pintaude, A. Sinatora, A. Matthews, Surf. Coat. Technol. 174-175 (2003) 891.

[48] J. Musil, Surf. Coat. Technol. 125 (2000) 322.

[49] F.W. Zok, A. Miserez, Acta. Mater. 55 (2007) 6365.

[50] O. Wanstrand, M. Larsson, P. Hedenqvist, Surf. Coat. Technol. 111 (1999) 247. 